\title{
Remote Fragmentations of Protonated Aromatic Carbonyl Compounds Via Internal Reactions in Intermediary Ion-Neutral Complexes
}

\author{
G. Thielking, U. Filges*, and H.-Fr. Grützmacher \\ Fakultät für Chemie der Universität Bielefeld, Bielefeld, Germany
}

\begin{abstract}
Protonated aromatic aldehydes and methyl ketones 1a-10a, carrying initially the proton at the carbonyl group, are prepared by electron impact-induced loss of a methyl radical from 1-arylethanols and 2-aryl-2-propanols, respectively. The aryl moiety of the ions corresponds to a benzene group, a naphthalene group, a phenanthrene group, a biphenyl group, and a terphenyl group, respectively, each substituted by a $\mathrm{CH}_{3} \mathrm{OCH}_{2}$ side-chain as remote from the acyl substituent as possible. The characteristic reactions of the metastable ions, studied by mass-analyzed ion kinetic energy spectrometry, are the elimination of methanol, the formation of $\mathrm{CH}_{3} \mathrm{OCH}_{2}^{+}$ions, and the elimination of an ester $\mathrm{RCOOCH}_{3}(\mathrm{R}=\mathrm{H}$ and $\mathrm{CH}_{3}$ ). The mechanisms of these fragmentations were studied by using D-labeled derivatives. Confirming earlier results, it is shown that the ester elimination, at least from the protonated aryl methyl ketones, has to proceed by an intermediate [acyl cation/arylmethyl methyl ether]-complex. The relative abundances of the elimination of methanol and of the ester decrease and increase, respectively, with the size of the aromatic system. Clearly, the fragmentation via intermediate ion-neutral complexes is favored for the larger ions. Furthermore, the acyl cation of these complexes can move unrestricted over quite large molecular distances to react with the remole $\mathrm{CH}_{3} \mathrm{OCH}_{2}$-side-chain, contrasting the restricted migration of a proton by 1,2-shifts ("ring walk") in these systems. (I Am Soc Mass Spectrom 1992, $3,417-426)$
\end{abstract}

$\mathrm{I}$ on-neutral complexes are important intermediates of unimolecular mass spectrometric fragmentations of organic ions [1]. Although their role is not obvious for most fragmentations of highly excited ions occurring in the ion source of a mass spectrometer, intermediary ion-neutral complexes influence the rate of the dissociations and the course of the reactions, in particular of metastable ions. Hence, a study of the reactions of intermediate ion-neutral complexes is of interest for a better theoretical understanding of gas-phase ion chemistry as well as for a reliable application of metastable ion techniques (i.e., tandem mass spectrometry) to structural analysis.

In many cases hydrogen atom exchanges and hydrogen atom abstractions that are mediated by ionneutral complexes and that neighbor the site of a simple bond cleavage are observed [1]. Fragmentations subsequent to more complicated internal ionneutral reactions and occurring at remote positions to the first bond cleavage are also known [1]. These latter fragmentations are of special interest because they uncover the mobility of the components within

\footnotetext{
* Taken in part from the doctoral thesis, Universität Bielefeld, 1986. Address reprint requests to H.-Fr. Grützmacher.
}

the complex in which they are bound by electrostatic forces intermediate in strength between a Van der Waal bond and a covalent chemical bond [2]. This mobility is very often described as a "free rotation" of the components within the complex. However, although the components are expected to move more or less independently of each other after passing a "locked rotor critical configuration" [3], they very likely do not move in a homogeneous electric field and probably are not "rotating freely" in the exact meaning of this phrase. The attractive ion-dipole and ion-induced-dipole forces in an "intimate" ion-neutral complex arising from an unimolecular fragmentation at low internal energy may be dominated by "proximity effects," i.e., local polarizabilities and local bond dipole moments. In fact, proximity effects within ion-molecule complexes in solution are well known, and such effects occurring in critical complexes or transition states are used to explain the outcome of enantioselective and diastereoselective synthetic reactions. Furthermore, theoretical calculations of ion-neutral complexes in the gas phase show that certain relative orientations of the components, for example, hydrogen bonded complexes [4], are more stable than others. The importance of such 
"stable" orientations of intermediate ion-neutral complexes for the kinetics and routes of the fragmentations is not yet clear, and more experimental facts about the migrational behavior of ions electrostatically attached to organic molecules and radicals are needed. This information may be gained by the study of more examples of fragmentations of metastable organic ions by internal ion-molecule reactions at sites remote from the initial bond cleavage process.

Longevialle and Botter [5a] have shown by several studies of the mass spectral fragmentations of steroidal diamines that the charged fragment can travel quite long molecular distances within an ion-neutral complex before it transfers a hydrogen atom at a remote position of the steroid. A further example of fragmentation by the migration of an ionic fragment and internal ion-molecule reaction, which has been studied in our laboratory, are benzaldehydes and acetophenones substituted by a methoxymethyl group and protonated at the carbonyl group [6]. These ions fragment metastably inter alia by the elimination of an ester molecule. This ester molecule arises from an electrophilic attack of an acyl cation on the methoxy group in an acyl cation/benzyl methyl ether complex formed by a protiolytic deacylation reaction (Scheme I).

The driving force for this reaction is undoubtedly the formation of very stable reaction products, i.e., a resonance stabilized benzyl cation and a stable ester molecule, allowing the intermediary ion-neutral complex an energetically much more favorable decomposition by the internal ion-molecule reaction than by direct dissociation. In fact, it has been shown [7] by varying the acyl substituent $\mathrm{RCO}$, that the fragmentation by the internal ion-neutral reaction occurs only as long as the direct dissociation is not favored by yielding an especially stable acyl cation $\mathrm{RCO}^{+}$. Another interesting modification of this model system is a change of the benzene nucleus by a larger aromatic group. This would permit the study of the mobitity of acyl cations attached to quite large aromatic molecules.

For the internal ion-neutral reaction to occur, the acyl cation formed from the carbonyl protonated ben- zaldehyde 1a (generated by electron impact-induced dissociation from the 1-phenylethanol derivative $\mathbf{1}$, Scheme II) or from the carbonyl protonated acetophenone 2a (from the 2-phenylpropane-2-ol derivative 2, Scheme II) has to move across the benzene ring to attack the methoxy group of the para-side-chain. An analogous ester elimination has been observed for metastable acyl naphthalenes protonated at the carbonyl group [8], and is especially abundant for the ions $3 a$ and $4 \mathbf{a}$ (prepared from the 2,6-disubstituted naphthalenes 3 and 4 , Scheme II) in spite of the increased distance between the protonated carbonyl group and the methoxymethyl side-chain. Obviously, the formyl cation and acetyl cation, respectively, arising from the proteolysis of the $C-C$ bond in these ions can move quite easily across the naphthalene ring before docking at the ether- $\mathrm{O}$ atom of the methoxymethyl side-chain.

To study this intramolecular ion-molecule reaction further and to discover additional examples of the migration of a formyl or an acetyl cation over large molecular distances, the fragmentations of the metastable ions 5a-10a (see Scheme II) were studied. These carbonyl protonated compounds are conveniently formed by electron impact-induced dissociation of the alcohols 5-10. The ions 5a and 6a contain the planar phenanthrene moiety and thus represent an extension of the naphthalenic ions $3 \mathbf{a}$ and $4 \mathbf{a}$. The iuns 7a-10a currespond to diphenyl and terphenyl derivatives, respectively, in which the benzene rings may rotate against each other. It was of interest to see whether this rotation has an effect on the migratory aptitude of the acyl cations across the aromatic rings.

\section{Experimental}

Compounds. The syntheses of 1-(4-methoxymethylphenyl)ethanol (1), 2-(4-methoxyphenyl)propanol (2), 1-(6-methoxymethyl-2naphthyl)ethanol (3), and 2-(6-methoxy-phenyl-2naphthyl)propanol (4) have been described previously
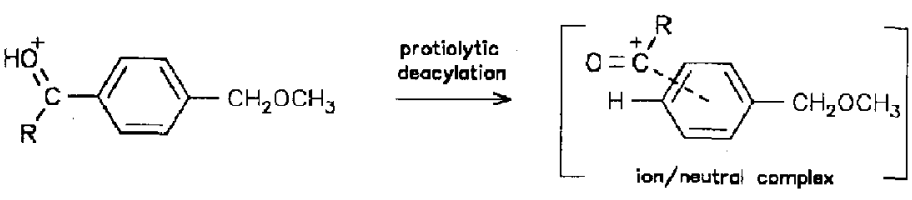

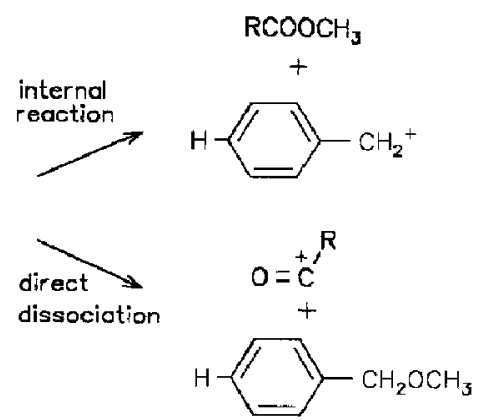



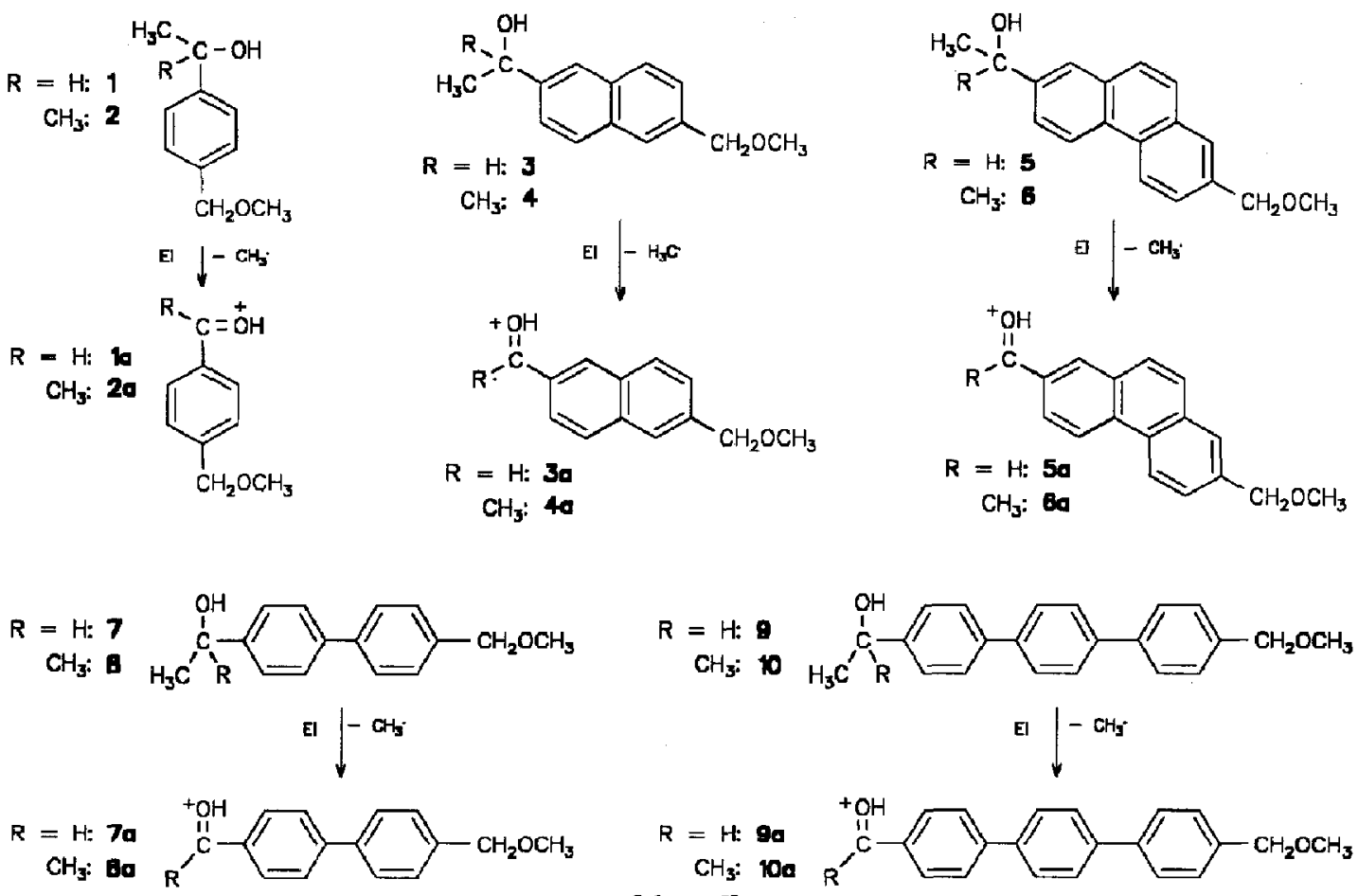
$R=H: 9 a$
$\mathrm{CH}_{3}: 100$

Scheme II

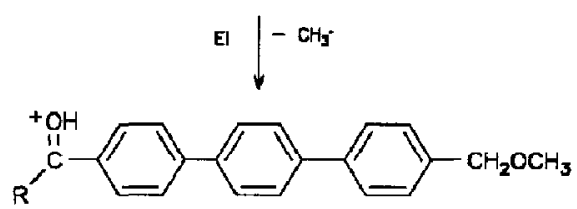

$[6,8]$. The mass-analyzed ion kinetic energy (MIKE) spectra of the ions a from these compounds were remeasured to ensure identical mass spectral conditions for all compounds of this study.

1-(7-Methoxymethyl-3-phenanthryl)ethanol (5) was prepared from 7-methyl-3-phenanthrene carboxylic acid by photobromination with $\mathrm{NBS} / \mathrm{CCl}_{4}$ and treatment of the monobromide with methanol to yield 7-methoxymethyl-3-phenanthrene carboxylic acid methyl ester (yield $57 \%, \mathrm{mp} 74^{\circ} \mathrm{C}$ ). Hydrolysis of the ester and reaction of the acid with $\mathrm{CH}_{3} \mathrm{Li}$ provided 3-acetyl-7-methoxymethyl-phenanthrene (yield $46 \%$ ), which was reduced to 5 (yield $99 \%, \mathrm{mp} 87-88^{\circ} \mathrm{C}$ ) with $\mathrm{LiAlH}_{4}$. 2-(7-Methoxymethyl-3-phenanthryl)propanol (6) was synthesized from the 7-methoxymethyl3-phenanthrene carboxylic ester by reaction with $\mathrm{CH}_{3} \mathrm{MgI} / \mathrm{THF}$ (yield 96\%). 1-(4'-Methoxymethyl-4-biphenyl)ethanol (7) was obtained by photobromination of 4-acetyl-4'-methylbiphenyl [9], followed by methanolysis in $\mathrm{CH}_{3} \mathrm{ONa} / \mathrm{CH}_{3} \mathrm{OH}$ of the monobromide to 4-acetyl-4'-methoxymethylbiphenyl (yield $86 \%, \mathrm{mp}=121-122{ }^{\circ} \mathrm{C}$ ), and reduction of the ketone with $\mathrm{LiAlH}_{4} / \mathrm{THF}$ (yield $93 \%$, mp 127-129 ${ }^{\circ} \mathrm{C}$ ). The deuterated derivative $7-d_{1}$ was prepared by the same reaction sequence but using LiAlD $_{4}$ in the last step. $7-d_{8}$ was synthesized starting from 4-methylbiphenyl by exchanging the aromatic $\mathrm{H}$ atoms by treatment $\mathrm{DCl} / \mathrm{D}_{2} \mathrm{O}$ at $250^{\circ} \mathrm{C}[10]$, acetylation of the resulting 4-methylbiphenyl- $d_{9}$, and reduction with LiAlH $_{4}$ as before. The D-content of $7-d_{8}$ was $D_{8} 16 \%, D_{7} 33 \%$, $\mathrm{D}_{6} 32 \%, \mathrm{D}_{5} 15 \%$, and $\mathrm{D}_{4} 4 \%$ (by mass spectrometry). 2-(4'-Methoxymethyl-4-biphenyl)propanol (8) was obtained from 4-acetyl-4'-methoxymethyl-biphenyl (see above) with $\mathrm{CH}_{3} \mathrm{MgI} / \mathrm{ether}$ (yield 94\%, mp 94-95 ${ }^{\circ} \mathrm{C}$ ). Similarly, 8- $\mathrm{d}_{3}$ was obtained from the ketone by reaction with $\mathrm{CD}_{3} \mathrm{MgI} / \mathrm{ether}$. 1-(4'-Methoxymethyl-4terphenyl)ethanol (9) was prepared by reduction of 4-acetyl-4'-methoxymethylterphenyl with $\mathrm{LiAlH}_{4}$ (yield 92\%). 9-d 1 was prepared similarly by using $\mathrm{LiAlD}_{4}, \mathrm{D}$-content $\mathrm{D}_{1}>95 \%$. The 4-acetylterphenyl derivative was obtained by Friedel-Crafts acetylation of 4-methylterphenyl, followed by photobromination with NBS, and methanolysis of the crude bromide. 2-(4'-Methoxymethyl-4-terphenyl)propanol (10) was synthesized from 4-acetyl-4'-methoxymethylterphenyl by reaction with $\mathrm{CH}_{3} \mathrm{Mgl} /$ ether (yield $67 \%$ ). All ODderivatives of the alcohols studied were obtained by repeated treatment of the alcohol with $\mathrm{D}_{2} \mathrm{O} / \mathrm{THF}$ to exchange the $\mathrm{OH}$ group, and a treatment of the inlet system and ion source of the mass spectrometer with $\mathrm{D}_{2} \mathrm{O}$ vapor prior to the measurement.

Mass spectrometry. The electron ionization mass spectra of 1-10 were obtained with a Finnigan MAT (Bremen, Germany) 311A mass spectrometer under the following conditions: electron energy $70 \mathrm{eV}$, ion source temperature $\sim 180^{\circ} \mathrm{C}_{r}$ introduction of the sample into the ion source by the direct insertion probe at ambient 
temperature, accelerating voltage $3 \mathrm{kV}$, mass resolution $\sim 1000$, recording of the mass spectra by a MAT SS200 data system.

The metastable ions 1a-10a were investigated with a double focusing mass spectrometer VG ZAB-2F (Manchester, UK) with the magnetic sector field preceding the electrostatic analyzer and equipped with a combined electron ionization/chemical ionization (CI) ion source. The following experimental conditions were used: electron energy $70 \mathrm{eV}$, electron trap current $50 \mathrm{~mA}$, accelerating voltage $6 \mathrm{kV}$, ion source temperature $-180^{\circ} \mathrm{C}$, mass resolution $\sim 1000$, sample admission by the direct probe inlet system. The ions a generated by electron impact were focused magnetically into the second field-free region preceding the electrostatic analyzer, and the unimolecular decompositions of these ions were recorded by scanning the deflecting voltage of the electrostatic analyzer.

\section{Results and Discussion}

The MIKE spectra of the ions 1a-10a are shown in Table 1 . It is seen clearly that the relative abundance of the elimination of an ester molecule increases in the two series of ions $1 a, 3 a, 5 a$, and $2 a, 4 a, 6 a$, mainly at the expense of the elimination of methanol. Similarly, the ions 7a-10a containing a diphenyl or a terphenyl unit decompose nearly exclusively by the loss of an ester molecule (at least formally, see below) and hardly by the elimination of methanol.

The initial step for both fragmentations is the transfer of the proton at the carbonyl group to the aromatic ring (Scheme III). Subsequently, the proton may cleave either of the two side chains by a protiolysis of the pertinent $\mathrm{C}-\mathrm{C}$ bond or migrate eventually to the methoxy group, inducing the elimination of methanol. In the former case the $\mathrm{CH}_{3} \mathrm{OCH}_{2}^{+}$ion is formed by a direct dissociation while the $\mathrm{CHO}^{+}$ion and the $\mathrm{CH}_{3} \mathrm{CO}^{+}$ion, respectively, are trapped in intermediate ion-neutral complexes, traverse the aromatic ring(s) assisted by the local bond dipole moment of the ether group, and eventually leave as ester molecules.

The MIKE spectra of the protonated diphenyl carbaldehyde $7 \mathbf{a}$ and of the terphenyl carbaldehyde $9 \mathbf{a}$ contain only small peaks for the loss of methanol. However, both the signals for the elimination of the ester and the formation of the ions $\mathrm{CH}_{3} \mathrm{OCH}_{2}^{+}$are large in contrast to the MIKE spectra of the polycyclic aromatic ions $3 \mathbf{a}$ and $\mathbf{5 a}$ (see Table 1). The release of the ions $\mathrm{CH}_{3} \mathrm{OCH}_{2}^{+}$by a protiolytic bond cleavage requires a migration of the proton from the carbonyl group of $7 \mathbf{a}$ or $9 \mathbf{a}$ across two and three benzene rings, respectively. In view of the slow proton migration around the naphthalene and phenanthrene rings it is rather surprising that the single bond between the benzene rings of ions $7 a$ and $9 a$ imposes apparently no barrier for the proton migration from one ring to
Table 1: MIKE spectra (\% rel. int. of total fragment ion current) of protonated aromatic carbonyls 1a-10a

\begin{tabular}{c||r|r|r|r|r|r|r|r|r|r} 
ion & $\mathbf{1 a}$ & $\mathbf{2 a}$ & $\mathbf{3 a}$ & $\mathbf{4 a}$ & $\mathbf{5 a}$ & $\mathbf{6 a}$ & $\mathbf{7 a}$ & $\mathbf{8 a}$ & $\mathbf{9 a}$ & $\mathbf{1 0 a}$ \\
\hline$-\mathrm{CO}$ & & - & 1 & - & - & - & 3 & & 4 & - \\
\hline$-\mathrm{CH}_{2} \mathrm{O}$ & 1 & 3 & 4 & 1 & 1 & 1 & - & - & & \\
\hline$-\mathrm{CH}_{3} \mathrm{OH}$ & 43 & 40 & 30 & 5 & 8 & 2 & 1 & 1 & - & - \\
\hline$-\mathrm{RCOOCH}_{3}{ }^{\mathrm{a}}$ & 9 & 33 & 46 & 92 & 81 & 92 & 22 & 92 & 32 & 86 \\
\hline $\mathrm{CH}_{3} \mathrm{OCH}_{2}{ }^{+}$ & 46 & 17 & 15 & - & 8 & - & 66 & & 52 & - \\
\hline $\mathrm{RCO}^{+\mathrm{a}}$ & - & 6 & - & - & - & 1 & - & 3 & & 1 \\
\hline other & - & - & $3^{\mathrm{b}}$ & $2^{\mathbf{b}}$ & $2^{\mathrm{c}}$ & $4^{\mathrm{d}}$ & $4^{\mathrm{e}}$ & $\mathbf{4}^{\mathrm{e}}$ & $8^{\mathrm{e}}$ & $12^{\mathrm{d}}$ \\
\hline
\end{tabular}

a 1a, 3a, 5a, 7a, 9a: R = H; 2a, 4a, 6a, 8a, 10a: $R=\mathrm{CH}_{3}$

b. $\mathrm{CH}_{3}=\mathrm{C}_{3} \mathrm{H}_{4} \mathrm{O}_{2}{ }^{d}-\mathrm{C}_{2} \mathrm{H}_{4} \mathrm{O}_{2}+\mathrm{C}_{2} \mathrm{H}_{3} \mathrm{O}^{\prime}-\mathrm{CH}_{3} \mathrm{O}$

the other. The ipso-protonated toluene is 15.7 $\mathrm{kcal} / \mathrm{mol}$ less stable than its other protomers [11], and a similar relative destabilization is expected for an ipso-protonated biphenyl or terphenyl derivative. Therefore, it is possible that the proton transfer from one benzene ring to the other in the diphenyl and terphenyl moiety of $7 a$ and $9 a$ does not occur by a 1,2-proton shift across the $\sigma$-bond between the benzene rings, but by a 1,4-shift between the $o^{-}$and $o^{\prime}$-positions of two rings (Scheme IV). The diphenyl group is twisted around the central $\sigma$-bond, and this would permît an antarafacial 1,4-sigmatropic shift allowed by the Woodward-I Ioffmann rules.

Assuming rapid hydrogen migrations between the rings of $7 a$ and $9 a$ to explain the abundant ions $\mathrm{CH}_{3} \mathrm{OCH}_{2}^{+}$in the MIKE spectra, it is difficult to explain the low abundance of the methanol elimination initiated by the same proton migration. A clue for the solution of this discrepancy is given by small peaks for the loss of CO in the MIKE spectra of $7 \mathrm{a}$ and 9a that are absent in the spectra of 1a, 3a, and 5a. This loss of $\mathrm{CO}$ indicates a different fragmentation behavior of the diphenyl and terphenyl derivatives $7 a$ and $9 \mathbf{a}$, and for these ions possibly the loss of the ester molecule $\mathrm{HCOOCH}_{3}$ may in fact be mimicked by consecutive losses of $\mathrm{CO}$ and $\mathrm{CH}_{3} \mathrm{OH}$. The loss of $\mathrm{CO}$ can occur by a proton transfer from the formyl cation to the aromatic system in the initially generated formyl cation/arylmethyl ether complex, and in the case of $7 \mathbf{a}$ and $9 a$ this process may be supported by the increased proton affinity (PA) of the aryl group in these ions (PA[benzene] $758.6 \mathrm{~kJ} / \mathrm{mol}$ [12]; PA[naphthalene] $814.5 \mathrm{~kJ} / \mathrm{mol}$ [12]; PA[diphenyl] $820.5 \mathrm{~kJ} / \mathrm{mol}$ [12]). Note that the proton transfer from $\mathrm{HCO}^{+}$to the aryl group within the ion-neutral complex represents also an additional mechanism for the transport of a proton from the carbonyl group to remote benzene rings of the ions $7 \mathbf{a}$ and $9 \mathbf{a}$, explaining the formation of abundant $\mathrm{CH}_{3} \mathrm{OCH}_{2}^{+}$ions in the MIKE spectra of these ions. Finally, separate experiments have shown [13] that benzyl methyl ether exhibits only a small peak of surviving $\mathrm{MH}^{+}$ions in its $\mathrm{CI}\left(\mathrm{CH}_{4}\right)$ mass spectrum, and most of the protonated ether molecules eliminate 


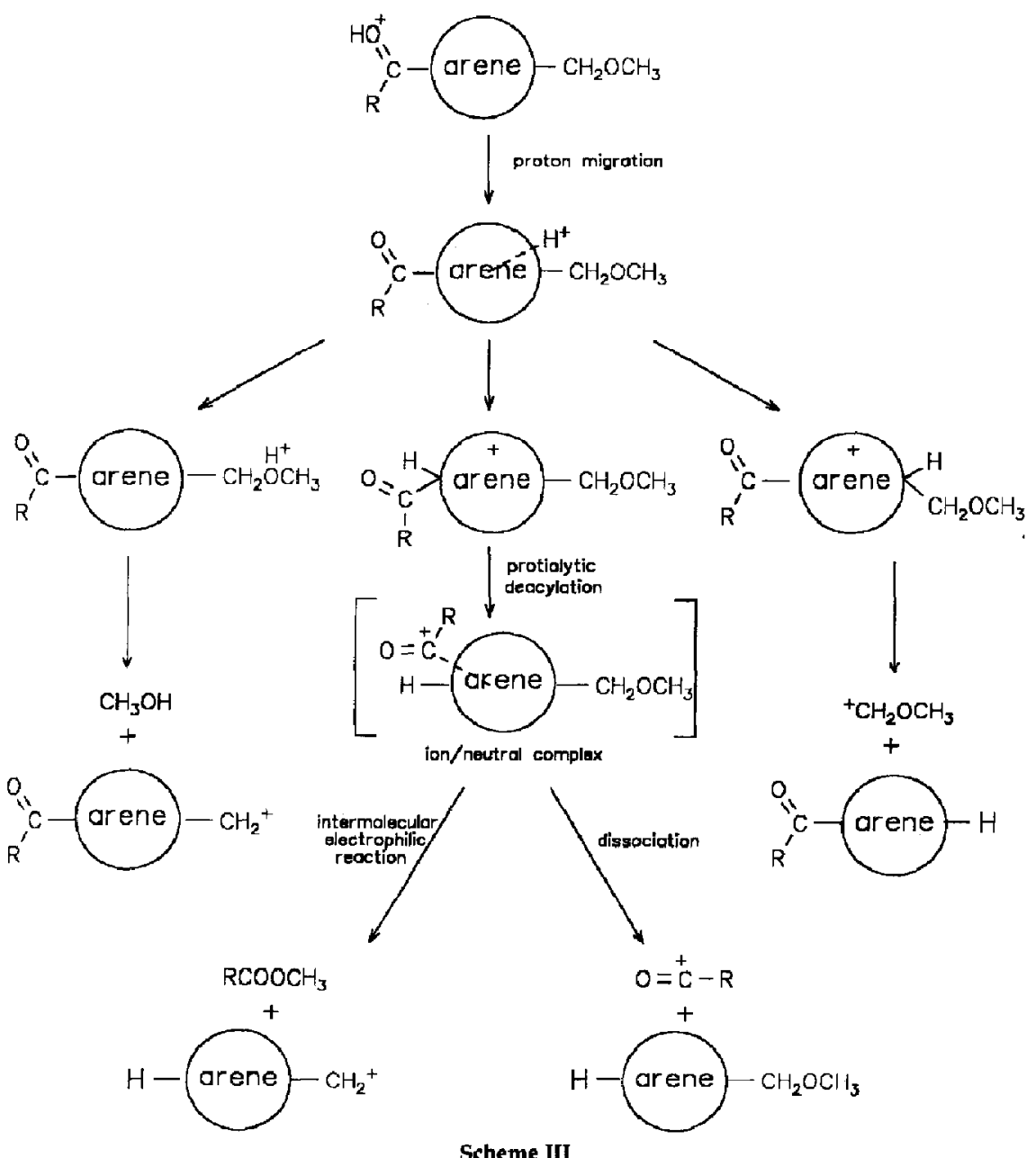

methanol immediately. Thus, a proton transfer from the $\mathrm{CHO}^{+}$ion to the polyphenylmethyl methyl ether within an intermediate ion-neutral complex formed by ions $7 \mathbf{a}$ and $9 a$, respectively, will not only release $a$ $\mathrm{CO}$ molecule but is immediately followed also by the loss of $\mathrm{CH}_{3} \mathrm{OH}$ (Scheme V).

The combined loss $\left[\mathrm{CO}+\mathrm{CH}_{3} \mathrm{OH}\right]$ by fast consecutive reactions is difficult to distinguish from the one-step elimination of $\mathrm{HCOOCH}_{3}$. One possibility is the use of specifically deuterated derivatives. To test these reactions $7 a-d_{1}$ and $9 a-d_{1}$, labeled at the aldehyde group, 9a(OD), labeled at the hydroxyl group, and $7 \mathrm{a}-\mathrm{d}_{8}$, labeled at all positions of the aromatic rings, were investigated (Scheme VI and Table 2). The ions $7 a-d_{1}$ and $9 a-d_{1}$ are expected to give rise specifically to the loss of $\mathrm{DCOOCH}$ if the ester molecule is generated by the electrophilic attack of the formyl cation on the ether- $\mathrm{O}$ atom within the intermediate complex. In contrast, the transfer of $\mathrm{D}^{+}$from the ion $\mathrm{DCO}^{+}$to the diphenyl and triphenyl system in this complex should result in a fast exchange $\mathrm{D}^{+}$for $\mathrm{H}^{+}$ by the hydrogen atoms at the aromatic rings. In this case, mainly " $\mathrm{HCOOCH}_{3}$ " $\left(\mathrm{CO}+\mathrm{CH}_{3} \mathrm{OH}\right)$ will be lost. Indeed, the MIKE spectra of the ions $7 a-d_{1}$ and 9a-d $\mathbf{d}_{1}$ exhibit a large peak for the apparent loss of $\mathrm{HCOOCH}_{3}$, and a contribution of the expected $\mathrm{DCOOCH}_{3}$ is not detected and must be less than $10 \%^{1}$.

The two-step mechanism is further corroborated by the MIKE spectrum of $7 \mathbf{a}-\mathbf{d}_{\mathbf{8}}$, which exhibits peaks for the losses of $\left(\mathrm{CO}+\mathrm{CH}_{3} \mathrm{OH}\right)$ and $\left(\mathrm{CO}+\mathrm{CH}_{3} \mathrm{OD}\right)$ of about equal intensity. This confirms an exchange between the two hydrogen atoms of the protonated formyl substituent and the $8 \mathrm{D}$ at the aromatic rings. However, these fragmentations are obviously associ-

\footnotetext{
${ }^{1}$ An elimination of $\mathrm{HCOOCH}_{3}$ as an intact molecule from $7 \mathrm{a}-\mathrm{d}_{1}$ and $9 \mathrm{a}-\mathrm{d}_{1}$ would be possible if a reversible $\mathrm{H} / \mathrm{D}$-exchange between $\mathrm{DCO}^{+}$ and the aromatic groups is assumed. However, this is difficult to understand in view of the rather different $\mathrm{PA}$ of $\mathrm{CO}$ and the respective aromatic groups.
} 
<smiles>CC[C@@H]1CCCC[C@@H]1c1ccc(COC)cc1</smiles><smiles>COCC1=C[C@H](C)[C@H](c2ccc(C(C)=O)cc2)C=C1</smiles>

ated with an isotope effect, and it is not possible to decide which portions of the ions $\left[\mathrm{a}-\mathrm{HCOOCH} \mathrm{C}_{3}\right]$ are formed by elimination of an intact ester $\mathrm{HCOOCH}_{3}$ or by the consecutive losses of $\mathrm{CO}$ and $\mathrm{CH}_{3} \mathrm{OH}$. Thus, the reactions of the protonated aldehydes $7 \mathrm{a}$ and $9 \mathrm{a}$ (and also $3 a$ and $5 a$ ) give information about the proton migration in these large aromatic systems, but the formation of an ion-neutral complex mediating the elimination of an ester molecule by an internal ionmolecule reaction is doubtful, although not excluded for the benzene, naphthalene, and phenanthrene ions 1a, $3 \mathbf{a}$, and $5 \mathbf{a}$.

In the case of the protonated acetyl arenes, the MIKE spectra (see Table 1) of the diphenyl and terphenyl ions 8a and 10a as well as those of the polycyclic aromatic ions $2 a, 4 a$, and $6 a$ show a decrease of the intensity for the elimination of methanol, but this
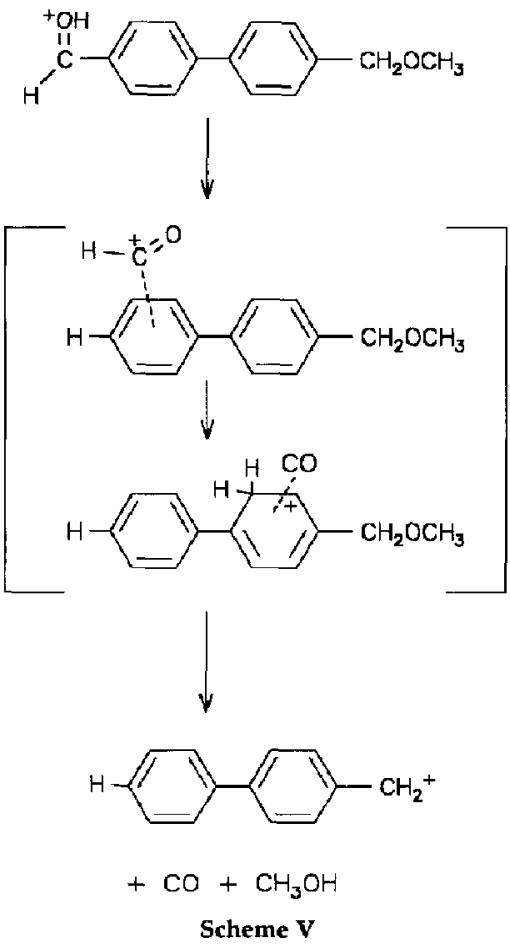

7-d.<smiles>[R]C(=O)c1ccc(C2=CC([2H])=C(COC)CC2)c([2H])c1</smiles><smiles>[R]O[C@H](O)c1ccc(-c2ccc(-c3ccc(CC)cc3)cc2)cc1</smiles><smiles>C#C</smiles><smiles>[R]C(=[OH+])c1ccc(-c2ccc(-c3ccc(COC)cc3)cc2)cc1</smiles>

$R=D: 90-d$ 
Table 2: MEKE spectra (\% rel. int. of total fragment ion current) of deuterated ions $7 a-d_{1}, 7 a-d_{3}, 8 a-d_{3}, 9 a-d_{1}, 9 a(O D)$, and 10(OD)

(see Scheme II for structure of ions)

\begin{tabular}{|c|c|c|c|c|c|c|}
\hline ion & $7 a-d_{1}$ & $7 \mathrm{a}-\mathrm{d}_{\mathrm{g}}$ & $8 \mathbf{a}-\mathbf{d}_{3}$ & $9 \mathrm{a}-\mathrm{d}_{1}$ & 9a(OD) & 10a(OD) \\
\hline. $\mathrm{CO}$ & 5 & 4 & - & 4 & 4 & . \\
\hline$-\mathrm{CH}_{3} \mathrm{OH}$ & 3 & 2 & 1 & 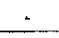 & - & - \\
\hline. $\mathrm{CH}_{3} \mathrm{OD}$ & . & 1 & 1 & . & - & - \\
\hline $\mathrm{R}_{\mathrm{H}} \mathrm{COOCH}_{3}{ }^{\mathrm{a}}$ & 38 & 28 & - & 29 & 32 & 86 \\
\hline $\mathrm{R}_{\mathrm{D}} \mathrm{COOCH}_{3}{ }^{\mathrm{b}}$ & . & 28 & 95 & $=$ & - & $\cdot$ \\
\hline $\mathrm{CH}_{3} \mathrm{OCH}_{2}{ }^{+}$ & 54 & 38 & - & 45 & 57 & - \\
\hline $\mathrm{R}_{\mathrm{D} \mathrm{CO}^{+} \mathrm{b}}$ & - & - & 3 & - & - & 2 \\
\hline other & - &. & - & $14^{E}$ & $3^{\mathrm{c}}$ & $10^{\mathrm{d}}$ \\
\hline
\end{tabular}

${ }^{a} \mathbf{R}_{\mathrm{H}}=\mathrm{H}$ or $\mathrm{CH}_{3}{ }^{\mathrm{b}} \mathrm{R}_{\mathrm{D}}=\mathrm{D}$ or $\mathrm{CD}_{3} \approx-\mathrm{C}_{2} \mathrm{H}_{3} \mathrm{O}$ a $-\mathrm{C}_{2} \mathrm{H}_{3} \mathrm{DO}$

time also the formation of ions $\mathrm{CH}_{3} \mathrm{OCH}_{2}^{+}$is negligible for all ions besides 2a. The MIKE spectrum of the protonated trideuteroacetyl diphenyl derivative $\mathbf{8 a -} \mathbf{d}_{3}$ (see Scheme VI) shows only a peak for the loss of $\mathrm{CD}_{3} \mathrm{COOCH}_{3}$, guaranteeing that the intact acetyl group is lost. This confirms the earlier results from a study of trideuteroacetylated benzene [6a] and naphthalene [6b] derivatives. Hence, the elimination of $\mathrm{CH}_{3} \mathrm{COOCH}_{3}$ does not correspond to consecutive losses of $\mathrm{CH}_{2}=\mathrm{C}=\mathrm{O}$ and $\mathrm{CH}_{3} \mathrm{OH}$, but represents exclusively a fragmentation by an internal ion-molecule reaction between the acetyl cation and the ether group in an intermediary ion-neutral complex. In fact, the $\mathrm{PA}\left[\mathrm{CH}_{2} \mathrm{CO}\right]=828.4 \mathrm{~kJ} / \mathrm{mol}[12]$ is much larger than the $\mathrm{PA}[\mathrm{CO}]$, and a proton transfer from the acetyl cation to the aromatic rings even of $8 \mathrm{a}$ and $10 \mathrm{a}$ is not very likely.

In view of the uncertainty with respect to a one-step or two-step elimination of $\mathrm{HCOOCH}_{3}$ from the protonated aldehydes it is advisable to restrict the discussion of the reactions of intermediate ion-neutral complexes to the fragmentations of the protonated arylmethyl ketones 2a, 4a, 6a, 8a, and 10a. Nevertheless, the same trends are also observed in the MIKE spectra of the protonated aromatic aldehydes $\mathbf{1 a}, \mathbf{3 a}, \mathbf{5} \mathbf{a}, \mathbf{7} \mathbf{a}$, and $9 a$. Contrary to $2 a$, the peak for the elimination of $\mathrm{CH}_{3} \mathrm{COOCH}_{3}$ dominates already in the spectrum of the 2,6-disubstituted naphthalenic ion $4 a$, and $92 \%$ of the fragment ion current in the MUKE spectrum of the phenanthrene derivative 6a corresponds to the ester. elimination. Similar high abundances for this process are observed in the MIKE spectra of the diphenyl and terphenyl derivatives $8 \mathrm{a}$ and $10 \mathrm{a}$. The increase of the relative abundances of the ions $\left[\mathrm{a}-\mathrm{CH}_{3} \mathrm{COOCH}_{3}\right]$ in the MIKE spectra of the protonated aryl-methyl ketones with the size of the aromatic system is quite large in spite of an increasing intramolecular distance between the acetyl group and the methoxymethyl side-chain. This distance between the location of the acetyl substituent at the aromatic ring and the ether- $O$ atom increases from approximately $5 \AA$ in $2 a$ to $6.6 \AA$ in 4a, to $9.3 \AA$ in $6 \mathbf{a}$ and $8 \mathbf{a}$, and eventually to $13.6 \AA$ in 10a.

Several possible explanations for this effect have to be considered. First, the elimination of an ester molecule, compared to the loss of methanol, may become more and more energetically favorable with increasing size of the aromatic moiety. The heats of formation of the relevant educt and product ions are not known. However, both competing fragmentations give rise to arylmethyl cations retaining the respective aromatic group. Thus it is not very likely, that the relative reaction enthalpy of the two competing eliminations varies so much in this series to account for the large intensity variations. Second, the PA of the aromatic group increases from 2a (benzene, $\mathrm{PA}=758.6$ $\mathrm{kJ} / \mathrm{mol}$ [12] to $6 \mathrm{a}$ (phenanthrene, $\mathrm{PA}=831.4 \mathrm{~kJ} / \mathrm{mol}$ [12]) or 9a (diphenyl, PA $=820.5 \mathrm{~kJ} / \mathrm{mol}$ [12]). As a consequence, the initial proton transfer from the carbonyl group to the aromatic ring should be favored in the larger ions. However, this effect would enhance the loss of methanol as well as the elimination of the ester molecule. Third, the polarizability of the aromatic group of the ions a increases in the series $2 a, 4 a$, $6 a$ and $2 a, 8 a, 10 a$, respectively, with the size of the aromatic system. This increases substantially the electrostatic attraction between an ion and the arylmethyl-ether fragment in an intermediate ion-neutral complex in this series and the stability of this complex. Very likely this effect is responsible for the specific increase of the probability of the ester elimination. Once the acetyl cation is formed by an initial proton migration to the aromatic ring, the cleavage of the $\mathrm{C}-\mathrm{C}$ bond of the acetyl substituent by protiolysis should be easier for the larger educt ions because of the formation of a more stable ion-neutral complex. Such a size effect has also been observed in the case of alkane elimination from aliphatic ether molecular ions [14]. In the present case the eventual elimination of a methyl acetate molecule by the internal ion-molecule reaction is favored by this "size effect." Note that this requires an urrestricted migration of the acyl cation over quite large intramolecular distances up to $-13 \AA$ in the case of 10a. Of course, the acetyl cation and the neutral ether molecule have not to be separated completely by this distance for "free rotation" in the intermediate complex. Instead, the cation may "drift" along the aromatic $\pi$-electron cloud but at a distance large enough to ensure the mobility of the ion.

Although it is quite clear that a large aromatic system with a large polarizability will favor the formation of an ion-neutral complex, the increase of the relative intensity of the ester elimination may be at least partly due to a decrease of the intensities of the competing fragmentations, i.e., the elimination of methanol and the formation of the ion $\mathrm{CH}_{3} \mathrm{OCH}_{2}^{1}$. These two latter processes require in the case of the larger ions a migration of a proton across several benzene rings to the methoxy group and the 
methoxymethyl side-chain, respectively. The migration of a proton within aromatic systems occurs by successive 1,2-shifts ("ring walk"), which are usually very fast. From the observation, that the additional proton in protonated tribenzylmethane and tetrabenzylmethane "scrambles" completely with the 15 and 20 hydrogen atoms, respectively, at the phenyl rings prior to a decomposition of these arenium ions, it has been inferred from the lifetime of metastable ions that the rate of the 1,2-proton shift exceeds $10^{6} \mathrm{~s}^{-1}$ [15]. Recently, Attina et al. [16] have determined this rate more directly from the isomerization rate of $\sigma$-complexes in the gas phase to be $1.6 \cdot 10^{9} \mathrm{~s}^{-1}$. However, this large rate refers only to a proton migration ("ring walk") within an individual benzene ring, and the ring junctions of condensed aromatic systems and very likely also the $\sigma$-bonds in polyphenyls may impose barriers to the ring walk around the complete aromatic system. This is indicated by several results. Thus, the main process of metastable $2 \mathbf{a}$ is the ester elimination, while protonated 1-acetyl-4-methoxymethyl-naphthalene, corresponding to an isomeric ion a with both side chains at the same benzene ring, decomposes mainly by the elimination of methanol [8]. An analysis of the competition between the losses of methanol and ester in other positional isomers of ion 2a has in fact revealed [8] that the elimination of methanol can compete only if the initial proton migration from the prolonated carbonyl group may proceed to the ring substituted by the methoxymethyl group. In this case no 1,2-proton shift across a ring junction is necessary. Furthermore, an estimation of the heats of formation of the various protomers of $2 \mathrm{a}$ by MNDO shows indeed the species carrying the proton at a carbon atom of the ring junction to be less stable by about $80 \mathrm{~kJ} / \mathrm{mol}$ [8]. In contrast to the step-by-step migration of the proton, the acetyl cation, bound only by electrostatic forces to the aromatic system, migrates by a reorientation of the acyl cation/arylmethyl methyl ether-complex (Scheme VII). This reorientation, perhaps assisted by the local dipole moment of the ether group in the methoxymethyl side-chain, allows the acetyl cation obviously to bridge quite large molecular distances and to induce remote fragmentations at a suitable functional group of the neutral component by internal ion-molecule reactions.

The suggested profound difference in the mechanisms of the migration of a proton and an acyl cation, respectively, in extended aromatic systems is corroborated by the MIKE spectra of protonated 1-acetyl-4methoxymethyl benzene and of protonated 4-acetyl4'-methoxymethyl-terphenyl 11 and its trideuteroacetyl analogue $11-d_{3}$. These protonated species generated by $\mathrm{CI}\left(\mathrm{CH}_{4}\right)$ are related to ions $2 \mathrm{a}$ and 10a, respectively, but are very likely mixtures of all possible protomers from the very beginning of their life. In the former case, the MIKE spectra of $2 a$ and of the isomers generated by $C I$ are nearly identical [13]. indicating that the protomers interconvert easily in this case. For the terphenyl ions $11 \mathrm{H}^{+}$and $11 \mathrm{H}^{+}-\mathrm{d}_{3}$, however, the MIKE spectra of 10a and of the CI product ions shown in Table 3 are rather different. The spectra of the ions generated by $\mathrm{CI}$ exhibit still the lass of $\mathrm{CH}_{3} \mathrm{COOCH}_{3}$ and of $\mathrm{CD}_{3} \mathrm{COOCH}_{3}$ (formed exclusively in the case of the trideuteroacetyl derivative $11 \mathrm{H}^{+}$) as the main process, but now distinct peaks for the elimination of methanol and of $\mathrm{CO}$ appear as well as peaks for the formation of the ions $\mathrm{CH}_{3} \mathrm{CO}^{+}\left(\mathrm{CD}_{3} \mathrm{CO}^{+}\right)$and the loss of $\mathrm{CH}_{3} \mathrm{OCH}_{2} \cdot$. In contrast, the peak for the loss of $\mathrm{C}_{2} \mathrm{H}_{4} \mathrm{O}_{2}$, very likely the combined loss of $\mathrm{CO}$ and $\mathrm{CH}_{3} \mathrm{OH}$, in the spectrum of 10a is missing in the other spectra. This is expected if protumers carrying the proton at the different benzene rings of the terphenyl unit are generated by CI (Scheme VII), but are not mutually interconverting with 10a formed by electron impact-induced dissociation of the propanol 10. The PA(terphenyl) is not known but should be similar to the PA of the related terphenylene of $830.5 \mathrm{~kJ} / \mathrm{mol}$ [12]. Thus, the carbonyl group is probably still the most basic center of the molecule (PA(acetophenone) $=859.4 \mathrm{~kJ} / \mathrm{mol}$ [12]). Nevertheless, the acidity of the

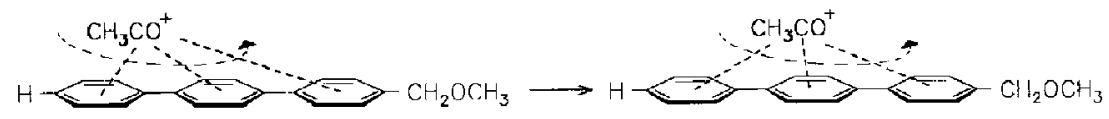

fast acetyl cation migration in ion/neutral complex

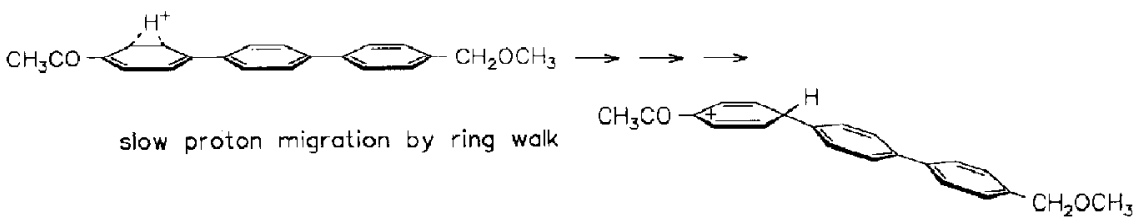

Scheme VII 


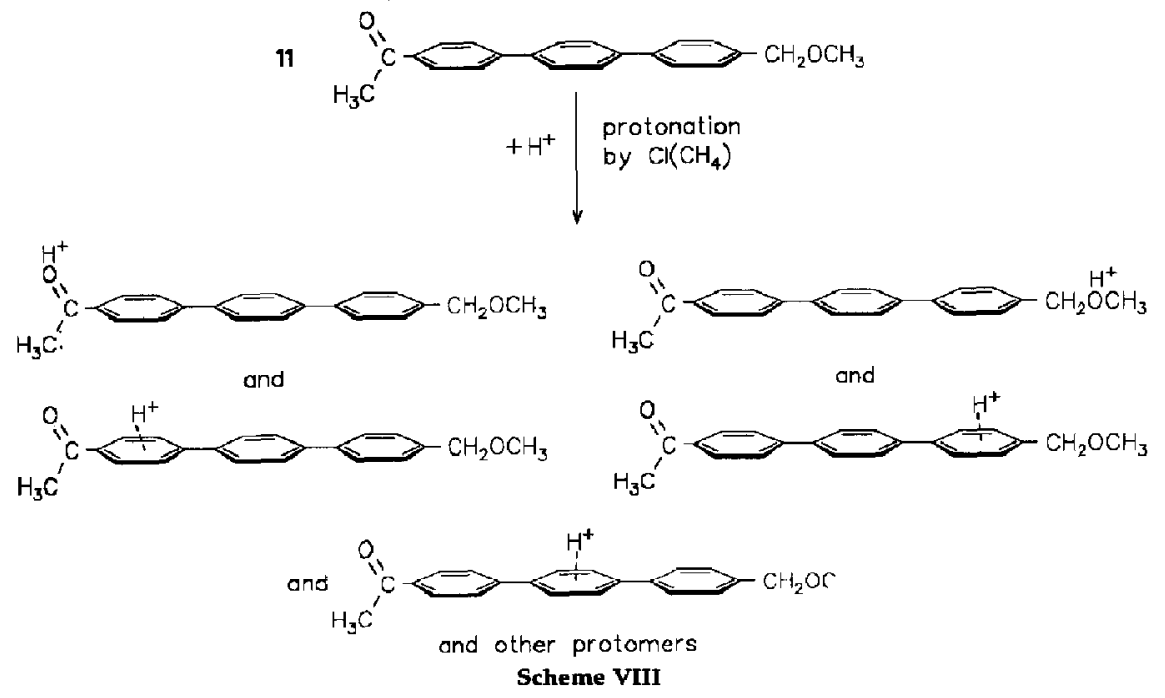

Table 3. MIKE spectra (\% rel. int. of totalfragment ion current) of protonated 4-acetyl-4'-methoxymethylterphenyl $\mathbf{1 1 H}^{+}$and 4-trideuteroacetyl-4'-methoxymethylterphenyl $11 \mathrm{H}^{+}-\mathrm{d}_{3}$, generated by $\mathrm{Cl}\left(\mathrm{CH}_{4}\right)$

\begin{tabular}{l||c|c|c} 
fragmentation & $\mathbf{1 1 \mathbf { H } ^ { + }}$ & \multicolumn{1}{|l|}{$\mathbf{H H}^{+} \cdot \mathbf{d}_{\mathbf{3}}$} & $\mathbf{1 0 a}$ \\
\hline \hline$-\mathrm{CO}$ & 18 & 12 & - \\
\hline$-\mathrm{CH}_{3} \mathrm{OH}$ & 14 & 10 & - \\
\hline$-\mathrm{CH}_{3} \mathrm{OCH}_{2}$ & 7 & 6 & - \\
\hline$-\left(\mathrm{CO}+\mathrm{CH}_{3} \mathrm{OH}\right)$ & - & - & 12 \\
\hline$-\mathrm{CH}_{3} \mathrm{COOC} \mathrm{H}_{3}$ & 54 & - & 86 \\
\hline$-\mathrm{CD}_{3} \mathrm{COOCH}_{3}$ & - & 59 & - \\
\hline $\mathrm{CH}_{3} \mathrm{CO}^{\prime}$ & 7 & - & 2 \\
\hline $\mathrm{CD}_{3} \mathrm{CO}^{*}$ & - & 13 & - \\
\hline
\end{tabular}

The spectrum of 10 a from Table 2 is included for comparison.

methane plasma in the $\mathrm{CI}$ ion source is large enough to add a proton to the different benzene rings of the 1-acetyl-4-methoxymethylterphenyl.

\section{Conclusion}

The results of the present study of the fragmentations of metastable ions 1a-10a corresponding to carbonylprotonated aromatic aldehydes and methyl ketones with different aromatic skeletons and carrying a methoxymethyl side-chain remote from the acyl substituent give interesting information about the role and properties of ion-neutral complexes formed as intermediates of unimolecular fragmentations in a mass spectrometer.

First, the elimination of a methyl formate and a methyl acetate molecule from the protonated aldehydes and methyl ketones, respectively, is observed for all metastable ions of type a, confurming earlier observations for ions containing a benzene or naphthalene system $[6 a, b, 8]$.

Second, the study of deuterated derivatives of the protonated diphenyl and terphenyl carbaldehydes 7a and $9 \mathrm{a}$ shows that the elements $\mathrm{C}_{2} \mathrm{H}_{4} \mathrm{O}_{2}$ of a methyl formate molecule are also lost by fast consecutive losses of $\mathrm{CO}$ and $\mathrm{CH}_{3} \mathrm{OH}$. This mechanism has been excluded in an earlier study [6a, 8] for the benzene and naphthalene ions 1a and 3a. The change of the reaction mechanism for $7 \mathrm{a}$ and $9 \mathrm{a}$ is attributed to the increased PA of the diphenyl and terphenyl group, abstracting a proton from $\mathrm{HCO}^{+}$within the intermediate ion-neutral complex and giving the formyl cation no chance to reach the distant ether group. In contrast, any deprotonation of the acetyl cation in the intermediate complexes generated from protonated methyl ketones can be excluded. These ions fragment by the loss of intact methyl acetate molecules.

Third, the fragmentations by loss of an ester molecule increase strongly with the size of polycyclic aromatic systems as well as of polyphenyl systems. This increase is attributed to two effects: assistance of the formation of the intermediate ion-neutral complex by the increasing polarizability of the aromatic group, and hindrance of the proton migration in the extended aromatic systems. The former effect is a further example of the "size" effect [14] operating on intermediate ion-neutral complexes and is particularly clear in this case because of the high polarizability of the $\pi$-electrons in aromatic rings. The latter effect is very interesting because fast proton shifts within an individual benzene ring are well known $[15,16]$. The present results indicate, however, that the ring junction of polycyclic aromatic systems and the $\sigma$-bonds separating the benzene rings in polyphenyl impose barriers to the proton migration by a step-by-step ring 
walk. In contrast, the acyl cation of the acyl cation/aromatic ether-complexes can obviously migrate easily and span as large an intramolecular distances as $-13 \AA$, separating initially the acyl group and the methoxymethyl side-chain in the terphenyl system. This in line with the assumed mobility and "free rotation" of the components of an intermediate ion-neutral complex.

\section{Acknowledgment}

The financial assistance of the Deutsche Forschungsgemeinschaft and additional help by the Fonds der Chemischen Industrie is gratefully acknowledged.

\section{References}

1. McAdoo, D. J. Mass Spectrom. Rev. 1988, 7, 363.

2. Shao, J. D.; Baer, T,; Morrow, J. C.; Fraser-Monteiro, M. J. Chem. Phys. 1987, 87, 5242.

3. Kondrat, R. W.; Morton, T. H. Org, Mass Spectrom. 1991, 26, 410.

4. Burgers, P. C.; Holmes, J. L.; Hop, C. E. C. A.; Postma, R.; Ruttnik, P. J. A.; Terlouw, J. K. I. Am. Chem. Soc. 1987, 109, 7315.

5. (a) Longevialle, P.; Botter, R. J. Chem. Soc, Chem. Commun. 1980, 823. (b) Longevialle, P.; Bouchoux, G.; Hoppilliard, Y.
Org. Mass Spectrom. 1989, 24, 919. (c) Longevialle, P.; Bouchoux, G.; Hoppilliard, Y. Org. Mass Spectrom. 1990, 25, 527.

6. (a) Filges, U.; Grützmacher, H.-Fr. Org. Mass Spectrom. 1986, 21, 673. (b) Filges, U.; Grützmacher, H.-Fr. Org. Mass Spectrom. 1987, 22, 444. (c) Grützmacher, H.-Fr.; Thielking, G. Org. Mass Spectrom. 1988, 23, 397.

7. Grützmacher, H.-Fr.; Thielking, G.; Wittneben, D.; Eikenberg, D. Int. J. Mass Spectrom. Ion Processes 1990, 98, 378.

8. Filges, U.; Grützmacher, H.-Fr. Int. J. Mass Spectrom. Ion Processes 1988, 83, 111

9. Byron, D. J.; Gray, G. W.; Wilson, R. C. J. Chem. Soc. (C) 1966,840 .

10. Westiuk, N. H.; Kadai, T. Can. J. Chem. 1973, 52, 1485; Ibid. $1974,53,2169$.

11. Heidrich, D.; Grimmer, M.; Sommer, B. Tetrahedran 1976 , 32,2027

12. Lias, S. G.; Bartmess, J. E.; Liebman, J. F.; Holmes, J. L.; Levin, R. D.; Mallard, W. G. J. Phys. Ref. Data 1988, 17, Suppl. I.

13. Unpublished results from this laboratory with U. Filges and G. Thielking.

14. McAdoo, D. J.; Hudson, C. E.; Traeger, J. C.; Grose, A.; Griffin, L. L. J. Am. Soc. Mass Spectrom. 1991, 2, 261.

15. Kuck, D.; Bäther, W.; Grützmacher, H.-Fr. J. Am. Chem. Soc. 1979, 101, 7154.

16. Attina, M.; Cacace, F.; Ricci, A. J. Am. Chem. Soc. 1991, 113, 5937 . 